\title{
Quantification of steroids in human and mouse plasma using online solid phase extraction coupled to liquid chromatography tandem mass spectrometry
}

\section{Ferdinand Haller}

Institute for Experimental Genetics, Helmholtz Zentrum Muenchen

\section{Cornelia Prehn}

Institute for Experimental Genetics, Helmholtz Zentrum Muenchen

Jerzy Adamski

Institute for Experimental Genetics, Helmholtz Zentrum Muenchen

\section{Method Article}

Keywords: liquid chromatography, tandem mass spectrometry, online solid phase extraction, steroid analysis

Posted Date: February 16th, 2010

DOI: https://doi.org/10.1038/nprot.2010.22

License: (c) (1) This work is licensed under a Creative Commons Attribution 4.0 International License.

Read Full License 


\section{Abstract}

\section{Introduction}

Steroids are powerful signalling molecules regulating a variety of physiological processes such as cell proliferation, cell differentiation, and reproduction. Variations in steroid concentrations may hint at hormonal imbalances or metabolic disorders that allow for a diagnosis of human diseases. The measurement of steroid hormone concentrations is relevant to basic research as well as clinical sciences. For example, the systematic generation of mouse mutants has led to a need for comprehensive phenotyping. As these mouse models may bear defects that affect steroid synthesis or homeostasis, knowledge of the mouse steroid metabolome could help to identify these mutants and connect phenotypes to their molecular cause ${ }^{1}$.Metabolic characterisation of a large human cohort recently led to the discovery of associations between phenotype, metabolome, and genotype as shown by us ${ }^{2}$. To expand our knowledge of the metabolome to other substance classes, a high-throughput, robust, sensitive and specific steroid phenotyping method is required. For several years, immunoassays have been the standard method for measuring steroid concentrations. Recently, liquid chromatography tandem mass spectrometry methods for steroid analysis have been developed that combine the advantages of immunoassays $\backslash$ (i.e. sensitivity) with the specificity of mass spectrometry ${ }^{3}$. This protocol describes a high-throughput method to analyze several different steroids in plasma. By using online-SPE coupled to LC-MS/MS, six different steroids $\backslash$ (androstenedione, testosterone, cortisone, cortisol, progesterone, $170 \mathrm{H}-$ progesterone) are readily quantifiable in human plasma, while three steroids $\backslash$ (androstenedione, testosterone, corticosterone) can be quantified in mouse plasma. The method requires a minimum of hands-on time by the experimenter while simultaneously providing concentrations of several interesting steroids.

\section{Reagents}

d8-Corticosterone $\backslash(\mathrm{C} / \mathrm{D} / \mathrm{N}$ Isotopes $) \mathrm{d} 4$-Cortisol $\backslash(\mathrm{C} / \mathrm{D} / \mathrm{N}$ Isotopes $) \mathrm{d}$-Progesterone $\backslash(\mathrm{C} / \mathrm{D} / \mathrm{N}$ Isotopes $)$ ${ }^{13} \mathrm{C}_{2}$-Testosterone $\backslash$ (Cambridge Isotope Laboratories) $170 \mathrm{H}$-Progesterone $\backslash$ (Sigma) Androstenedione $\backslash$ (Steraloids) Cortisol \(Sigma) Cortisone \(Sigma) Progesterone \(Sigma) Testosterone \(Sigma) Acetonitrile $\backslash\left(\mathrm{HPLC}\right.$ grade, Roth) Methanol $\backslash\left(\mathrm{HPLC}\right.$ grade, Merck) $\mathrm{ZnSO}_{4} \backslash$ (Merck)

\section{Equipment}

Allure Biphenyl column $3 \mu \mathrm{m} ; 50 \mathrm{~mm}$ x $2.1 \mathrm{~mm} \backslash$ (Restek) Oasis HLB column $15 \mu \mathrm{m} ; 20 \mathrm{~mm}$ x $2.1 \mathrm{~mm} \backslash$ (Waters) $4000 \mathrm{Q}$ TRAP triple quadrupole mass spectrometer with a Turbo V source \(Applied Biosystems) Analyst software 1.4.2 \(Applied Biosystems) HPLC system consisting of two HPLC pumps $\backslash$ (one of them a binary gradient pump), an autosampler, a column oven with a built-in 6 port switching valve, and matching controlling unit e.g. Shimadzu LC-20AB, LC-20AD, SIL-20AC, CTO-20, and CBM-20A I (Shimadzu) 


\section{Procedure}

A. Sampling of blood 1. collect blood from subject $\backslash$ (human or mouse) 2. prepare EDTA plasma 3. store plasma at $-80^{\circ} \mathrm{C}$ before use B. Preparation of precipitation agent containing internal standards 1 . dissolve $50 \mathrm{~g} / \mathrm{LnSO}_{4}$ in water 2. mix $\mathrm{ZnSO}_{4}$ solution 1:1 with methanol $\backslash(\mathrm{v} / \mathrm{v})$ to get the precipitation agent 3. dilute internal standards in precipitation agent: ${ }^{13} \mathrm{C}_{2}$-Testosterone $1.5 \mathrm{ng} / \mathrm{mL} \backslash$ (final concentration); d4-Cortisol $7.5 \mathrm{ng} / \mathrm{mL} \backslash$ (final concentration); d9-Progesterone $1.5 \mathrm{ng} / \mathrm{mL} \backslash$ (final concentration); d8-Corticosterone $15 \mathrm{ng} / \mathrm{mL} \backslash$ (final concentration) 4 . place at $-20^{\circ} \mathrm{C}$ before use $\mathrm{C}$. Sample preparation 1. mix $50 \mu \mathrm{L}$ plasma with $100 \mu \mathrm{L}$ precipitation agent 2. vortex mix for $60 \mathrm{~s} 3$. incubate at $4{ }^{\circ} \mathrm{C}$ for 30 min with continuous shaking 4 . centrifuge at $14000 \mathrm{rpm}$ at $4{ }^{\circ} \mathrm{C}$ for $10 \mathrm{~min} 5$. transfer supernatant to deep well plate for measurement $D$. Chromatographic separation of samples 1. prepare solvents for chromatography; methanol:water $\backslash(5: 95)$ for solid phase extraction; acetonitrile:water:formic acid $\backslash$ (10:90:0.1) as solvent $A$ for gradient run; acetonitrile:formic acid $\backslash(100: 0.1)$ as solvent $B$ for gradient run 2. equilibrate chromatographic system with solvents $\backslash$ (gradient flow rate is $0.5 \mathrm{~mL} / \mathrm{min}$; online-SPE flow rate is $3 \mathrm{~mL} / \mathrm{min} 3$. inject $80 \mu \mathrm{L}$ of supernatant via autosampler 4 . apply gradient and valve switching information $\backslash$ (sample is enriched on online-SPE column and eluted in backflush onto the analytical column) from table $1 \mathrm{E}$. MS/MS analysis 1 . measure samples in positive mode using an ESI source 2 . set ion source parameters to $\mathrm{CUR}=20 ; \mathrm{CAD}=6$; IS $=4500 ; \mathrm{TEM}=600 ; \mathrm{GS} 1=40 ; \mathrm{GS} 2=553$. use the multiple reaction monitoring $\backslash(\mathrm{MRM})$ mass transitions given in table 14 . for calibration run standards in the following concentrations: $0.1,0.19,0.39,0.78,1.56,3.13,6.25,12.5,25 \mathrm{ng} / \mathrm{mL}$ for androstenedione, testosterone, progesterone, and 170H-progesterone; $0.98,1.95,3.91,7.81,15.63,31.25,62.5,125,250$ $\mathrm{ng} / \mathrm{mL}$ for cortisone, cortisol, and corticosterone 5. also run appropriate blanks $\backslash$ (steroid stripped plasma) and quality control samples 6. evaluate results using Analyst 1.4.2 software \(Applied Biosystems)

\section{Timing}

For preparation of 100 samples: hands-on time 2-3 h For measurement of 100 samples: about $8.5 \mathrm{~h} \backslash$ (no hands-on time, performed by autosampler and LC-MS/MS system)

\section{Critical Steps}

Chromatography solvents and the precipitation agent should be prepared fresh for each run. Pipetting steps before addition of internal standards are critical and should be performed as exactly as possible.

\section{Anticipated Results}

Typical results for human and mouse plasma are shown in Figures 1 and 2, respectively.

\section{References}


1. V. Gailus-Durner, H. Fuchs, L. Becker et al., Nat Methods $2 \backslash(6), 403 \backslash(2005)$. 2. T. Illig, C. Gieger, G. Zhai et al., Nat Genet $\backslash(2009)$. 3. F. Z. Stanczyk, J. S. Lee, and R. J. Santen, Cancer Epidemiol Biomarkers Prev $16 \backslash(9), 1713 \backslash(2007)$.

\section{Figures}

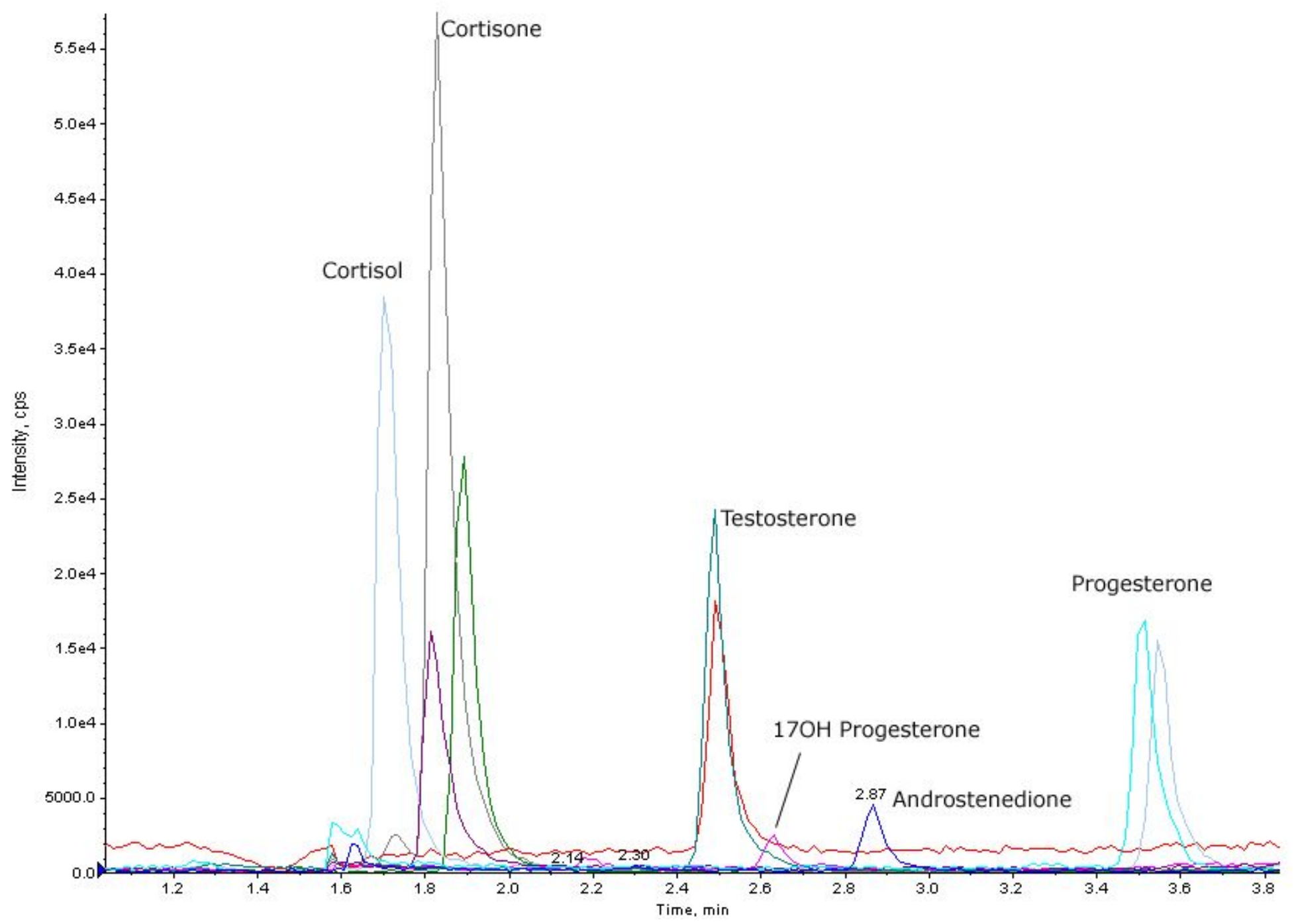

Figure 1

Representative chromatogram of measured steroids in human plasma (including internal standards) 


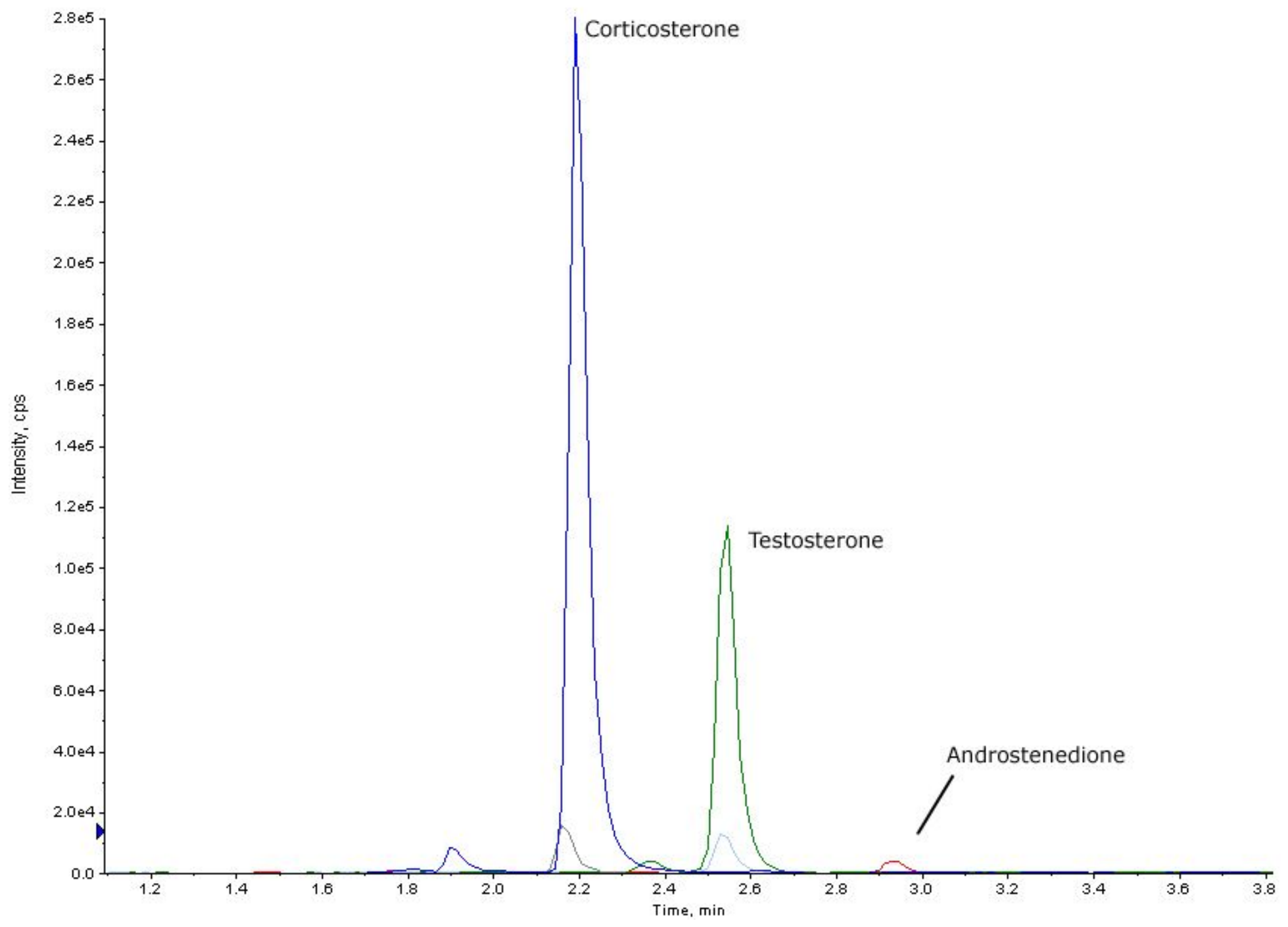

Figure 2

Representative chromatogram of measured steroids in mouse plasma (including internal standards) 


\begin{tabular}{|c|c|}
\hline Time & Concentration of B \\
\hline 0 & $42 \%$ \\
\hline 1 & $42 \%$ \\
\hline 2.8 & $62 \%$ \\
\hline 3.3 & $80 \%$ \\
\hline 3.4 & $100 \%$ \\
\hline 3.8 & $100 \%$ \\
\hline 3.9 & $42 \%$ \\
\hline 4.5 & $42 \%$ \\
\hline
\end{tabular}

\begin{tabular}{|l|l|l|l|l|l|l|}
\hline Substance & $\begin{array}{l}\text { Q1 } \\
\text { mass }\end{array}$ & $\begin{array}{l}\text { Q3 } \\
\text { mass }\end{array}$ & DP & EP & CE & CXP \\
\hline $\begin{array}{l}170 \mathrm{H} \\
\text { progesterone }\end{array}$ & 331.3 & 97.1 & 50 & 10 & 41 & 6 \\
\hline Androstenedione & 287.2 & 97.2 & 81 & 10 & 35 & 6 \\
\hline Corticosterone & 347.2 & 121.1 & 76 & 10 & 33 & 8 \\
\hline Cortisone & 361.2 & 163.2 & 76 & 10 & 33 & 10 \\
\hline Cortisol & 363.2 & 121.1 & 86 & 10 & 33 & 6 \\
\hline Progesterone & 315.2 & 109.1 & 51 & 10 & 37 & 8 \\
\hline Testosterone & 289.2 & 97.2 & 81 & 10 & 33 & 6 \\
\hline
\end{tabular}

\section{Figure 3}

Table 1 Gradient for the separation of steroids: the 6 port switching valve was set to the inject position after $1 \mathrm{~min}$. After $3.5 \mathrm{~min}$ the switching valve was switched back to the load position. Below MRM parameters for tandem mass spectrometry are shown. 